\title{
ESTUDO DA RESISTÊNCIA DE CONCRETOS COM AREIA DE FUNDIÇÃO E CINZA DE CASCA DE ARROZ
}

\section{Study of resistance of concrete with sand of foundation and gray of rice bark}

\author{
Cristiane Carine dos Santos' ${ }^{1}$, Diorges Carlos Lopes ${ }^{2}$
}

Recebido em 26 de abril de 2017; aceito em 14 de setembro de 2017; disponível on-line em 07 de novembro de 2017.

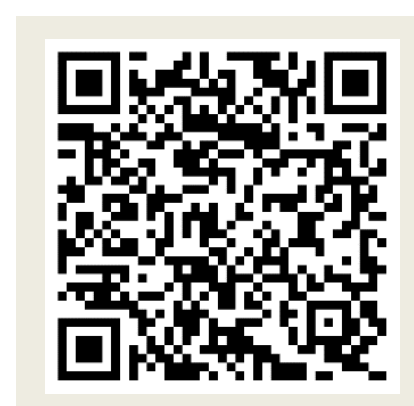

PALAVRAS CHAVE:

Resíduos;

Adições minerais;

Areias residuais;

Meio ambiente;

Impactos ambientais.

\section{KEYWORDS:}

Waste;

Mineral additions;

Residual sands;

Environment;

Environmental impacts.

\footnotetext{
* Contato com o autor:
}

\begin{abstract}
RESUMO: As ações relacionadas ao meio ambiente tornam-se cada vez mais intensas, necessitando-se encontrar alternativas para minimizar os impactos continuamente causados pelo desenvolvimento humano. Há inúmeras alternativas para reutilizar resíduos como constituintes do concreto. No Brasil a produção de arroz é intensa, gerando grande volume de resíduos. Outros resíduos que podem ser reutilizados são as areias de fundição. Contudo, a presente pesquisa buscou substituir parcialmente o cimento pela cinza de casca de arroz e a areia natural pela areia de fundição, a fim de melhorar as propriedades do concreto e diminuir os impactos ambientais. A partir das substituições parciais desses resíduos em misturas com somente um dos resíduos, e posteriormente com os dois resíduos simultaneamente, analisou-se a influência proporcionada ao concreto. Avaliou-se a resistência à compressão axial e a resistência à tração. Com a obtenção dos resultados constatou-se que os traços com somente areia de fundição tiveram um aumento de resistência, e os traços moldados com apenas cinza de casca de arroz e com os dois resíduos juntos mantiveram-se próximos do traço referência. Mesmo assim, pode-se afirmar que é viável a reutilização desses resíduos, pois além de melhorar as propriedades do concreto, também contribuem para a diminuição do consumo das matérias primas, auxiliando na preservação ambiental.
\end{abstract}

ABSTRACT: The actions related to the environment become increasingly intense, needing to find alternatives to minimize the impacts continuously caused by human development. There are numerous alternatives to reuse waste as constituents of concrete. In Brazil, rice production is intense, generating a large volume of waste. Other wastes that can be reused are foundry sands. However, the present research sought to partially replace cement by rice husk ash and natural sand by casting sand in order to improve concrete properties and reduce environmental impacts. From the partial substitutions of these residues in mixtures with only one of the residues, and later with the two residues simultaneously, the influence given to the concrete was analyzed. The axial compressive strength and the tensile strength were evaluated. With the results obtained it was found that the traces with only smelting sand had an increase of resistance, and the traces molded with only rice husk ash and with the two residues together remained close to the reference trace. Even so, it can be said that it is feasible to reuse these wastes, because besides improving the properties of concrete, they also contribute to the reduction of the consumption of raw materials, helping in the environmental preservation.

\footnotetext{
${ }^{1}$ e-mail: cristianecdossantos@hotmail.com (C. C. Santos)

Engenheira Civil, Mestranda em Engenharia Civil, Universidade Federal de Santa Maria.

${ }^{2}$ e-mail: diorges.lopes@unijui.edu.br (D. C. Lopes)

Engenheiro Civil, Mestre, Professor, Universidade Regional do Noroeste do Estado do Rio Grande do Sul.
} 


\section{INTRODUÇÃO}

Cada vez mais os cuidados com o meio ambiente devem ser intensificados, sendo que uma das alternativas que vem trazendo grande contribuição é a utilização de resíduos que podem melhorar as propriedades do concreto e consequentemente auxiliar em relação à sustentabilidade, ao invés de serem descartados de forma inadequada.

No Estado do Rio Grande do Sul, a economia está fortemente acoplada às atividades desenvolvidas na agricultura. Entre elas a produção de grande volume de arroz, o que acaba gerando uma enorme quantidade de resíduos sólidos derivados das atividades de processamento e beneficiamento, identificados como casca de arroz e cinzas resultantes dessa casca. Entretanto, esses resíduos são classificados como grandes responsáveis pela poluição e contaminação, e quando não gerenciados e destinados adequadamente causam sérios impactos ao meio ambiente e a saúde das pessoas (IRGA, 2012).

Devido às consequências geradas pelo grande número de resíduos sólidos, surgiram vários estudos sobre a reutilização dos mesmos no concreto, sendo que a viabilidade da substituição parcial da cinza de casca de arroz (CCA) em concretos já foi comprovada, através de resultados satisfatórios como: aumento da resistência à compressão, maior durabilidade do concreto, economia de cimento. Nesse contexto a utilização da CCA torna-se uma das soluções para o problema ambiental ocasionado pela deposição desse resíduo, reduzindo as áreas necessárias para descarte agroindustrial e minimizando os riscos de poluição ao meio ambiente (POUEY, 2006).

Outros resíduos sólidos que também causam preocupações relacionam-se as indústrias de fundição. Resíduos que são constituídos principalmente pelas chamadas areias residuais ou areias de fundição. Quando as areias no processo de fundição tornam-se inutilizáveis, os resíduos devem ser descartados e depositados em aterros, seguindo todas as normas estabelecidas pelas licenças da
Fundação Estadual de Proteção Ambiental (FEPAM, 2003). Esses aterros requerem muitos cuidados e monitoramentos, caso contrário geram inúmeros problemas ambientais, por causa do grande volume de resíduos e principalmente em relação ao custo das empresas com manutenção e construção de novas valas. Como solução para o grande volume dessas areias, torna-se necessário um gerenciamento adequado visando alternativas de reutilização.

No entanto, entre os diversos estudos e também com os avanços tecnológicos, percebemos que a área da construção civil tem a capacidade de proporcionar uma solução para os descartes de resíduos gerados nesse âmbito, tanto da cinza de casca de arroz como areias de fundição, com a possibilidade de incluí-los na área da construção civil, como materiais de construção. Assim, tornando possível a redução do custo dos produtos e principalmente a diminuição da emissão de resíduos ao meio ambiente.

\subsection{OBJETIVO}

O objetivo desta pesquisa consistiu em analisar a viabilidade técnica de utilização de resíduos de cinza de casca de arroz e areia de fundição em concretos, em misturas incorporando os resíduos separadamente e com os dois resíduos na mesma mistura.

\section{SUSTENTABILIDADE NA CONSTRUÇÃO CIVIL}

\subsection{ADIÇÕES MINERAIS}

De acordo com Mehta e Monteiro (2014), as adições minerais são materiais silicosos, finamente moídos, que adicionado ao concreto em teores relativamente grandes, geralmente na faixa de 20 a $50 \%$ de massa de cimento Portland, promovem melhorias no concreto. Estas melhorias estão no fato de causar uma redução considerável na porosidade das pastas e refinar os grãos de hidróxido de cálcio. A tabela 1 apresenta a classificação das adições minerais conforme Mehta e Monteiro (2014). 


\begin{tabular}{c|c}
\multicolumn{2}{c}{ TABELA 1: Classificação das adições minerais. } \\
\hline Classificação & Tipos de Adições \\
\hline Cimentantes & Escória granulada de alto forno \\
\hline Cimentantes e Pozolânicas & Cinzas volantes com alto teor de cálcio \\
\hline Superpozolanas & $\begin{array}{c}\text { Sílica ativa } \\
\text { Metacaulim } \\
\text { Cinza de casca de arroz }\end{array}$ \\
\hline Pozolanas comuns & Cinzas volantes com baixo teor de cálcio \\
& Argilas Calcinadas \\
\hline Pozolanas pouco reativas & Materiais naturais (origem vulcânica e sedimentar) \\
\hline Adições inertes (filler) & Escória de alto forno resfriada lentamente \\
Cinzas de forno \\
Escória de caldeira
\end{tabular}

FONTE: Metha e Monteiro (2014).

Isaia, Furquim e Gastaldini (2009) relatam que substituições de parte do cimento por adições minerais atuam de acordo com suas particularidades, principalmente em função de sua finura, atividades química e física ou ainda quantidade na mistura, as quais proporcionam diferentes interações com a pasta.

Com o intuito de reduzir o impacto ambiental global por meio da redução das emissões de gás carbônico (CO2), há uma crescente busca por adições minerais, pois além de diminuírem os custos quando incorporadas ao cimento Portland, também melhoram as propriedades do concreto e contribuem para a sustentabilidade. Entre as adições minerais mais estudadas e utilizadas destaca-se a cinza de casca de arroz, que é caracterizada como um subproduto agroindustrial, proveniente da queima da casca de arroz, podendo ser por meio da queima a céu aberto (sem controle de temperatura), pela combustão controlada ou ainda em fornos industriais.

Um dos fatores que contribuem para a crescente utilização da CCA é a grande quantidade deste resíduo que se produz no Brasil, principalmente no estado do Rio Grande do Sul. Conforme a Companhia Nacional de Abastecimento (2016) a produção de arroz é a terceira maior do país, com $5,3 \%$ da produção total dos produtos cultivados, ficando atrás apenas da produção de soja e milho.

Portanto, a utilização desta pozolana é de grande interesse entre os pesquisadores, devido às características apresentadas, e também através de estudos que comprovam a sua eficácia em relação às propriedades do concreto.

\subsection{AREIA DE FUNDIÇÃO}

Um dos subprodutos da indústria de fundição é a areia de fundição de materiais ferrosos e não ferrosos. A areia de sílica é utilizada na confecção de moldes, machos e núcleos para a fabricação de peças de metal, sendo reciclada e reutilizada inúmeras vezes no decorrer dos processos. Quando a areia estiver em um estágio inservível para o processo de fundição, ela passa a ser descartada e denominada "areia de fundição" (SIDDIQUE; SINGH, 2011).

Segundo a NBR 10004 (ABNT, 2004) a areia de fundição, que é utilizada para confecção de moldes de peças metálicas, é classificada como resíduo não perigoso, porém, dependendo de cada situação ou processo, pode apresentar alguns poluentes, como: metais (ferro, alumínio, níquel, cromo, chumbo, zinco, etc.) e resinas fenólicas, que podem afetar o ambiente quando destinado ou manuseado de forma inadequada.

Adegas (2007) realizou um estudo onde concluiu que, somente no Rio Grande do Sul, são produzidas aproximadamente 8.600 toneladas de areia de fundição ao ano, entre areias verdes e areias fenólicas. Conforme o estudo, $81 \%$ das fundições do Estado descartam a areia em aterros 
licenciados pela FEPAM (centrais de resíduos ou próprios) e $19 \%$ em locais não licenciados. Assim, o problema ambiental não é resolvido e o investimento no reuso desta areia em novos produtos ou materiais é muito pequeno.

Dentre as pesquisar realizadas até 0 momento pode-se perceber a eficiência de concretos com substituições parciais de areia natural por areia de fundição, pois como ela apresenta grãos mais finos que a areia natural, preenche melhor os vazios do concreto, contribuindo para a melhor hidratação e aumento da resistência do mesmo. Além de melhorar as propriedades do concreto contribuem para diminuição da poluição relacionada ao seu descarte inadequado e preservação de recursos naturais.

\section{MATERIAL E MÉTODOS}

Para o desenvolvimento desta pesquisa foram executados corpos de prova utilizando-se diferentes concentrações de agregados e resíduos. Desta forma, inicialmente realizou-se a aquisição e a caracterização dos materiais empregados nas misturas utilizadas para a confecção dos corpos de prova, como: areia média, areia de fundição, cimento, cinza de casca de arroz e brita 1. Depois da caracterização desses materiais definiram-se os diferentes traços de dosagem de cada amostra de concreto utilizada neste estudo.

Dentre os diferentes traços de dosagem, considerou-se um traço referência, sem substituição de cimento e agregados por resíduos, e os traços com diferentes porcentagens de substituição parcial, do cimento por cinza da casca de arroz e de areia natural por areia de fundição na mistura do concreto.

\subsection{CARACTERIZAÇÃO DOS MATERIAIS UTILIZADOS}

\subsubsection{CIMENTO}

O tipo de cimento utilizado para a confecção dos corpos de prova foi o CP II-E-32, por ser um cimento sem adição pozolânica em sua composição e também por ser possível o seu uso em diversos tipos e etapas de obras.

Na Tabela 2 está representada a composição químicas do cimento, e as características física podem ser observadas na Tabela 3.

TABELA 2: Composição química do cimento CP II-E-32.

\begin{tabular}{l|c}
\multicolumn{1}{c|}{ COMPONENTES QUÍMICOS } & $\begin{array}{c}\text { FAIXA DE CONCENTRAÇÃO } \\
\text { (\%) }\end{array}$ \\
\hline Silicato tricálcico $\left(\mathrm{C}_{3} \mathrm{~S}\right)$ & $20-70$ \\
\hline Silicato dicálcico $\left(\mathrm{Ca}_{2} \mathrm{Si}\right)$ & $10-60$ \\
\hline Ferro-aluminato de cálcio $\left(\mathrm{C}_{4} \mathrm{AFe}\right)$ & $5-15$ \\
\hline Sulfato de cálcio $\left(\mathrm{CaSO}_{4}\right)$ & $2-8$ \\
\hline Aluminato tricálcico $(\mathrm{C3A})$ & $1-15$ \\
\hline Carbonato de cálcio $\left(\mathrm{CaCO}{ }_{3}\right)$ & $0-10$ \\
\hline Óxido de magnésio $(\mathrm{MgO})$ & $0-6$ \\
\hline Óxido de cálcio $(\mathrm{CaO})$ & $0-3$ \\
\hline
\end{tabular}

TABELA 3: Características físicas do cimento CP II-E-32

\begin{tabular}{c|c} 
PROPRIEDADE & RESULTADO \\
\hline Finura \# 0,075 (\%) - (NBR 11579-ABNT, 2013) & 0,44 \\
\hline Tempo de pega (hs) - (NBR NM 65-ABNT, 2003) & $04: 46$ \\
\hline Massa específica (g/cm³) - (NBR NM 23-ABNT, 2001) & 3,035 \\
\hline
\end{tabular}




\subsubsection{CINZA DE CASCA DE ARROZ}

A cinza de casca de arroz, um dos resíduos substituído no concreto, foi adquirida na Indústria Cereais Passo da cidade de Itaqui-RS, identificada como "Micro sílica MS - 325". Na Tabela 4 pode ser observada a caracterização física deste material.

\subsubsection{AREIA MÉDIA (NATURAL)}

A areia média utilizada foi proveniente comércio local. Na Tabela 5 estão representadas as suas características físicas.

\subsubsection{AREIA DE FUNDIÇÃO}

A areia de fundição utilizada foi doada pela Empresa FUNDIMISA do município de
Santo Ângelo - RS. Para os ensaios de caracterização desse material foram utilizadas as mesmas normas da areia média (natural), em que os resultados estão apresentados na Tabela 6.

\subsubsection{BRITA 1}

Como agregado graúdo utilizou-se a brita 1 , em que as características deste material estão dispostas na Tabela 7.

\subsection{6 ÁGUA}

Para a moldagem dos corpos de prova utilizou-se água potável proveniente da rede de abastecimento da Universidade Federal de Santa Maria.

TABELA 4: Características da microssílica da cinza de casca de arroz.

\begin{tabular}{c|c} 
PROPRIEDADE & RESULTADO \\
\hline Finura \# 0,075 (\%) - (NBR 11579-ABNT, 2013) & 0,28 \\
\hline Massa específica $\left(\mathrm{g} / \mathrm{cm}^{3}\right)-($ NBR NM 23-ABNT, 2001) & 1,84 \\
\hline
\end{tabular}

\begin{tabular}{c|c}
\hline \multicolumn{2}{|c}{ TABELA 5: Características da areia natural. } \\
\hline PROPRIEDADE & RESULTADO \\
\hline Diâmetro máx. (mm) - (NBR NM 248-ABNT, 2003) & 1,2 \\
\hline Módulo de finura - (NBR NM 248-ABNT, 2003) & 1,9 \\
\hline Massa específica $\left(\mathrm{g} / \mathrm{cm}^{3}\right)-(\mathrm{NBR}$ 9776-ABNT, 2003) & 2,60 \\
\hline Massa unitária solta $\left(\mathrm{kg} / \mathrm{dm}^{3}\right)-(\mathrm{NBR} N M \mathrm{N5}-\mathrm{ABNT}, 2006)$ & 1,53 \\
\hline
\end{tabular}

TABELA 6: Características da areia de fundição.

\begin{tabular}{c|c} 
PROPRIEDADE & RESULTADO \\
\hline Diâmetro máx. $(\mathrm{mm})-($ NBR NM 248-ABNT, 2003) & 0,6 \\
\hline Módulo de finura - (NBR NM 248-ABNT, 2003) & 1,16 \\
\hline Massa específica $\left(\mathrm{g} / \mathrm{cm}^{3}\right)-($ NBR 9776-ABNT, 2003) & 2,43 \\
\hline Massa unitária solta $\left(\mathrm{kg} / \mathrm{dm}^{3}\right)$ - (NBR NM 45-ABNT, 2006) & 1,33 \\
\hline & FONTE: Autoria própria.
\end{tabular}

TABELA 7: Características físicas do agregado graúdo.

\begin{tabular}{c|c} 
PROPRIEDADE & RESULTADO \\
\hline Diâmetro máx. (mm) - (NBR NM 248-ABNT, 2003) & 19,0 \\
\hline Módulo de finura - (NBR NM 248-ABNT, 2003) & 6,75 \\
\hline Massa específica $\left(\mathrm{g} / \mathrm{cm}^{3}\right)-($ NBR NM 53-ABNT, 2002) & 2,93 \\
\hline Absorção $(\%)-(\mathrm{NBR} N M$ 53-ABNT, 2002) & 1,24 \\
\hline Massa unitária compac. $\left(\mathrm{kg} / \mathrm{dm}^{3}\right)-(\mathrm{NBR} N M$ 45-ABNT, 2006) & 1,69 \\
\hline
\end{tabular}




\subsection{MÉTODO DE DOSAGEM E MISTURAS}

Uma das principais etapas, e que requer muita atenção é o processo de dosagem, sendo uma atividade de extrema importância, porque além de estabelecer as quantidades de cada material constituinte do concreto, também influencia nas características responsáveis por alcançar um bom desempenho no produto final, relacionadas à qualidade e a economia.

Depois de finalizados os ensaios de caracterização dos materiais constituintes do concreto, foi possível calcular o traço de referência e executar as moldagens. Para a realização desta pesquisa utilizou-se o Método de Dosagem da ABCP (2010), que é um método baseado em tabelas, sendo calculado de maneira simples e desenvolvido os passos para obterem-se as devidas proporções dos materiais.

Estabeleceu-se um abatimento de tronco de cone de 80 a $100 \mathrm{~mm}$, sendo que para obter um determinado abatimento, a quantidade de água depende do tamanho máximo, da forma, da textura e da granulometria do agregado graúdo e miúdo.

Depois de calculados os traços, estabeleceu-se a quantidade de material necessária para a moldagem de 10 corpos de prova por traço, sendo 8 deles utilizados para obter a resistência à compressão nas idades de 7, 14, 21 e 28 dias, 2 corpos de prova para cada idade, e 2 corpos de prova para o ensaio de resistência à tração por compressão diametral, rompidos aos 28 dias de idade.

Após a determinação do traço referência, foram moldados os corpos de prova com, $5 \%, 10 \%$, $15 \%$ e $20 \%$ de substituição parcial do cimento pela microssílica da cinza de casca de arroz e substituição parcial da areia natural pela areia de fundição, primeiro em misturas separadas e em seguida os dois resíduos em uma mesma mistura.

\subsection{ENSAIOS E PROCEDIMENTOS EXPERIMENTAIS}

\subsubsection{RESISTÊNCIA À COMPRESSÃO AXIAL}

A avaliação da resistência à compressão axial do concreto foi realizada com corpos de prova cilíndricos de dimensões $10 \times 20 \mathrm{~cm}$. Por meio de uma prensa normatizada determinou-se a resistência do concreto na idade de 28 dias a partir das datas de moldagem dos corpos de prova. Os procedimentos foram realizados conforme a NBR 5739 (ABNT, 2007), sendo que o corpo de prova deveria ser centrado na prensa, de maneira que o seu eixo ficasse alinhado com o da prensa, para que a resultante das forças passasse pelo centro.

\subsubsection{ENSAIO DE RESISTÊNCIA À TRAÇÃO POR COMPRESSÃO DIAMETRAL}

A análise da resistência à tração por compressão diametral ocorreu por meio de dois corpos de prova cilíndricos para cada traço, de dimensões $10 \times 20 \mathrm{~cm}$, após 28 dias da data de moldagem. O corpo de prova foi posicionado em repouso ao longo de uma geratriz, sobre o prato da máquina de compressão, conforme descrito pela NBR 7222 (ABNT, 2011). A carga foi aplicada continuamente, sem choque, com crescimento constante da tensão de tração, a uma velocidade de $0,05 \pm 0,02 \mathrm{MPa} / \mathrm{s}$ até a ruptura do corpo-de-prova.

\section{RESULTADOS E DISCUSSÕES}

\subsection{RESISTÊNCIA À COMPRESSÃO AXIAL}

Com relação à resistência à compressão axial, por meio dos resultados obtidos no rompimento dos corpos de prova, elaborou-se o gráfico apresentado na Figura 1 com todos os traços e suas resistências obtidas aos 7 dias de idade do concreto. Pode-se perceber que a maior resistência foi atingida pelo traço sem substituição de resíduos (traço referência - RF), chegando aos 24,9 Mpa de resistência à compressão. Nos traços em que se substituiu apenas a areia natural pela areia de fundição (F) atingiram resistências maiores que os traços em que foram substituídos o cimento pela cinza da casca de arroz (M). Já os traços com a substituição da areia natural pela areia de fundição e do cimento pela cinza da casca de arroz (FM) atingiram resistências menores que os traços moldados somente com a substituição de um dos resíduos, exceto os traços FM (15\%) e FM (20\%), que resultaram em 16,5 $\mathrm{MPa}$ e $14,7 \mathrm{MPa}$ respectivamente. 
Por meio da Figura 2, apresentada a seguir, pode-se verificar que todos os traços obtiveram resistência à compressão menor que o traço referência (RF), que atingiu 33,5 Mpa aos 28 dias de idade do concreto, exceto os traços F5 e F10, que atingiram 36,4 Mpa e 34,1 Mpa, respectivamente. Nos demais traços com cinza de casca de arroz (M) e com os dois resíduos na mesma mistura (FM), pode-se perceber que os resultados ficaram próximos e que todos os traços com apenas cinza de casca de arroz resultaram em resistência à compressão superior aos traços com os dois resíduos misturados, exceto o traço FM15 que resultou em 28,7 Mpa, sendo 3,7 Mpa maior que o traço M15.

Ao analisar a Figura 2, percebe-se que as resistências à compressão do concreto variaram bastante, sendo que o aumento de resistência com a substituição da areia natural por areia de fundição pode ser explicada pela sua composição granulométrica, sendo que se obteve para o módulo de finura da areia natural 1,9 e o módulo de finura da areia de fundição 1,16 , Dessa maneira a areia de fundição preencheu melhor os vazios do concreto e ocorreu uma melhor hidratação, aumentando assim a resistência.

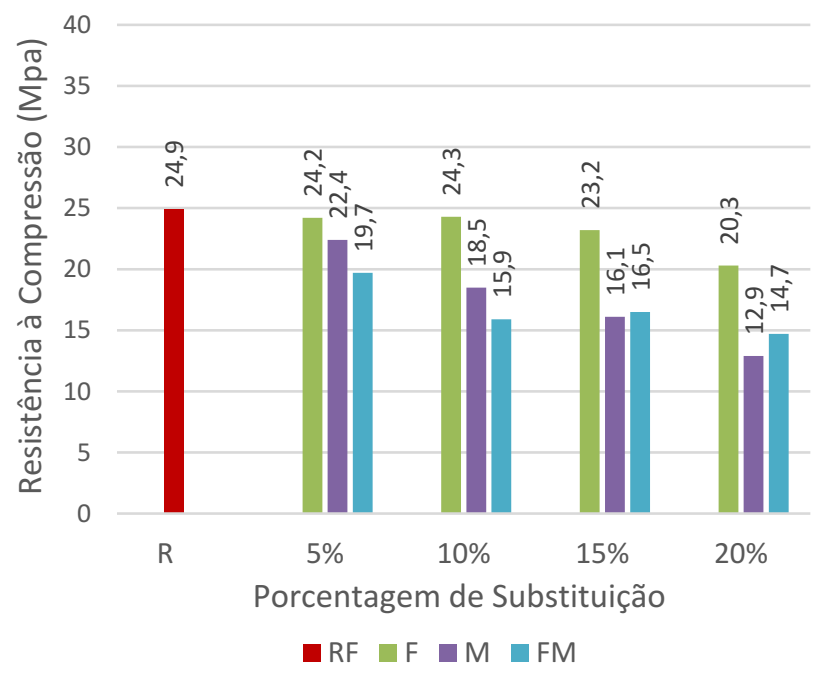

FIGURA 1 - Resistência à Compressão do concreto dos três tipos de misturas aos 7 dias de idade.

FONTE: Autoria própria.

\subsection{RESISTÊNCIAS À TRAÇÃO POR COMPRESSÃO DIAMETRAL DO CONCRETO}

Por meio dos resultados ilustrados na Figura 3 pode-se perceber que o traço referência (RF) atingiu 3,23 $\mathrm{MPa}$ de resistência à tração por compressão diametral, valor inferior à maioria dos resultados encontrados nas misturas com substituição dos resíduos. Todos os traços moldados apenas com a substituição da areia natural pela areia de fundição (F) obtiveram resistências maiores que o traço referência (RF), em que a maior resistência alcançada foi de 4,39Mpa, obtida pelo traço com substituição de $10 \%$ de areia natural por areia de fundição (F10). A resistência resultante dos traços moldados somente com a substituição do cimento pela cinza da casca de arroz atingiu valores próximos dos traços com apenas areia de fundição, mas inferiores que os mesmos, sendo que o traço que mais se aproximou foi o M5, atingindo 4,19Mpa de resistência. Já os traços em que foram substituídos os dois resíduos, obtiveramse resistências menores que os traços moldados com a substituição de apenas um deles, em que a menor resistência encontrada ocorreu com o traço FM15, com resistência de 2,88Mpa e a maior resistência atingida foi pelo traço FM10, com 3,55Mpa.

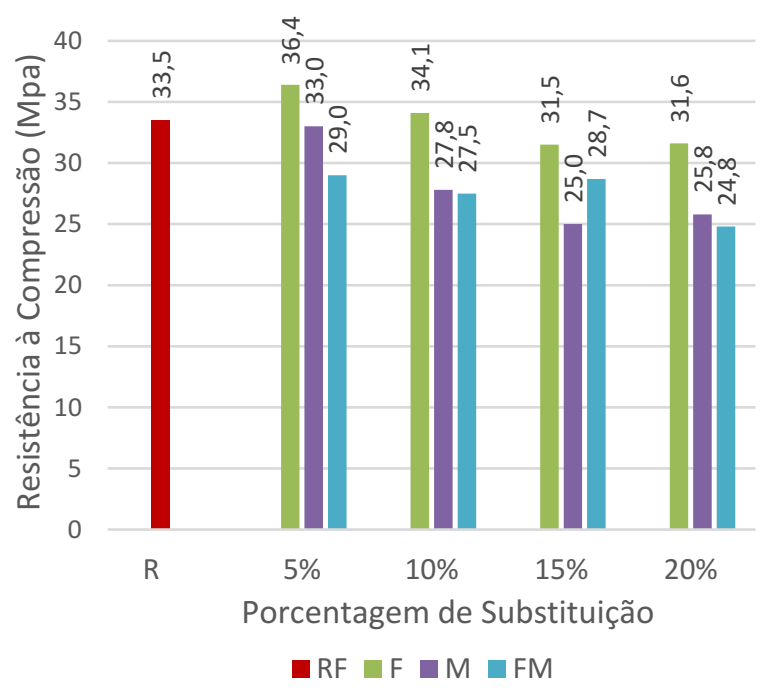

FIGURA 2 - Resistência à Compressão do concreto dos três tipos de misturas aos 28 dias de idade. FONTE: Autoria própria. 


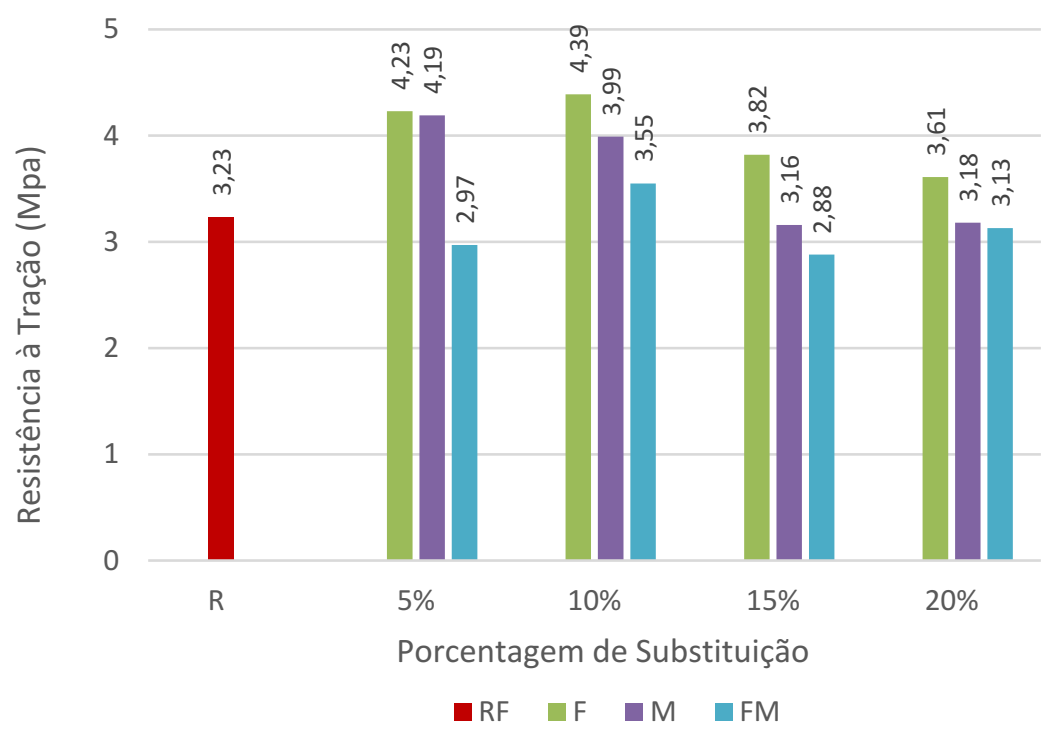

FIGURA 3 - Resistência à tração por compressão diametral do concreto dos três tipos de misturas aos 28 dias de idade.

FONTE: Autoria própria.

\section{CONSIDERAÇÕES FINAIS}

Portanto, ao finalizar este estudo pode-se concluir que as substituições de resíduos por materiais que compõem o concreto é uma importante alternativa, pois apesar de melhorar algumas propriedades do concreto, reduzem o uso de matérias-primas, diminuem as poluições ao meio ambiente, diminuindo os impactos ambientais causados pelo homem, que é o foco principal desta pesquisa.

Desta forma, pode-se concluir para este estudo que a adição desses resíduos ao concreto é viável e pode ser reconhecida pelo mercado da construção civil, pois muitos traços superam a resistência obtida pelo traço sem adição de resíduos. Mas vale frisar que, para esses traços de concreto serem produzidos em grande escala, necessitam de maiores estudos, principalmente em relação à composição química dos resíduos, e também sobre a microestrutura do concreto, que talvez consiga esclarecer melhor os resultados obtidos.

\section{REFERÊNCIAS BIBLIOGRÁFICAS}

ADEGAS, R. G. Perfil ambiental dos processos de fundição ferrosa que utilizam areias no estado do Rio Grande do Sul. Dissertação (Mestrado). Universidade Federal do Rio Grande do Sul, Porto Alegre, 2007.
ASSOCIAÇÃO BRASILEIRA DE CIMENTO PORTLAND. Guia básico de utilização do cimento portland. 7.ed. São Paulo, 2002. 28p.

ASSOCIAÇÃO BRASILEIRA DE NORMAS TÉCNICAS NBR 10004: Resíduos sólidos - Classificação. Rio de Janeiro, 2004.

NBR 11579: Cimento Portland - determinação da finura por meio da peneira 200

. NBR NM 23: Cimento Portland e outros materiais em pó: determinação da massa específica. Rio de Janeiro, 1998. 4p.

. NBR NM 65: Cimento Portland - determinação do tempo de pega. Rio de Janeiro, 2002. 6p.

- NBR NM 248: Agregados - determinação da composição granulométrica. Rio de Janeiro, 2001. 5p.

. NBR 9776: Agregados - Determinação da massa específica de agregados miúdos por meio do frasco Chapman. Rio de Janeiro, 2003. 8p.

.NBR NM 45: Agregados - Determinação da massa unitária e do volume de vazios. 2006. 8p.

. NBR NM 53: Agregado graúdo - determinação de massa específica, massa específica aparente e absorção de água. Rio de Janeiro. 2002; 4p.

NBR 5739: Ensaios de compressão de corpos-deprova cilíndricos. Rio de Janeiro, 2007. 9p.

NBR 7222: Concreto e argamassa Determinação da resistência à tração por compressão diametral de corpos de prova cilíndricos. 2011. 5 p. 
COMPANHIA NACIONAL DE ABATECIMENTO (CONAB). Disponível em:<

http://www.conab.gov.br/conteudos.php?a=1253\&>.

Acesso em: 22 de agosto de 2016.

FUNDAÇÃO ESTADUAL DE PROTEÇÃO AMBIENTAL. Relatório sobre a geração de resíduos sólidos industriais no estado do Rio Grande do Sul, Rio Grande do Sul, 2003.

IRGA. Instituto Riograndense do Arroz. Fundação Estadual de Pesquisa Agropecuária, 2 jul. 2012. Disponível em:<www.fepagro.rs.gov.br/.../20120702100451revista _pag_v17_n1_on>. Acesso em: 20 agosto 2015.

ISAIA, G. C.; FURQUIM, P.; GASTALDINI, A. L. G. Análise estatística de variáveis influentes na microestrutura e durabilidade de concretos com adições minerais. Ambiente Construído, Porto Alegre, v. 9, n. 1, p. 07-23, jan./mar. 2009.

MEHTA, P. K. MONTEIRO, P. Concreto: Microestrutura, Propriedades e Materiais. Ibracon 2014.

POUEY, M. T. F. Beneficiamento da cinza de casca de arroz residual com vistas à produção de cimento composto e/ou pozolânico. 2006. Tese (Doutorado em Engenharia Civil) - Universidade Federal do Rio Grande do Sul, Porto Alegre, BRRS, 2006.

SIDDIQUE, R.; SINGH, G. Utilization of waste foundry sand (WFS) in concretemanufacturing. Resources, Conservation and Recycling, Volume 55, Issue 11, September 2011, Pages 885-892, ISSN 0921-3449. 